\title{
Experimental analysis of a Flat Plate Pulsating Heat Pipe with Self-ReWetting Fluids during a Parabolic Flight Campaign
}

Anselmo Cecere ${ }^{1}$, Davide De Cristofaro ${ }^{1}$, Raffaele Savino ${ }^{1}$, Vincent Ayel ${ }^{2}$, Thibaud Sole-Agostinelli ${ }^{2}$, Marco Marengo $^{3}$, Cyril Romestant ${ }^{2}$, Yves Bertin ${ }^{2}$

${ }^{1}$ Department of Industrial Engineering-Aerospace Section, University of Naples “Federico II" 80 P. le V. Tecchio, 80125 Naples, Italy

${ }^{2}$ Institut PPrime, Department of Fluid, Thermal sciences and Combustion, UPR 3346 1, avenue Clément Ader, 86961 Futuroscope Chasseneuil Cedex

${ }^{3}$ School of Computing, Engineering and Mathematics, Cockcroft Building, C531, Lewes Road, University of Brighton, Brighton BN2 4GJ, UK

\begin{abstract}
A Flat Plate Pulsating Heat Pipe (FPPHP) filled with an ordinary liquid (water) and a self-rewetting mixture (dilutes aqueous solutions of long-chain alcohols with unusual surface tension behaviour) is investigated under variable gravity conditions on board a 'Zero-g' plane during the $65^{\text {th }}$ Parabolic Flight Campaign of the European Space Agency. The FPPHP thermal performance in terms of evaporator and condenser temperatures, start-up levels and flow regimes is characterized for the two working fluids and a power input ranging from 0 to $200 \mathrm{~W}$ (up to $17 \mathrm{~W} / \mathrm{cm}^{2}$ at the heater/evaporator wall interface). The experimental set-up also includes a transparent plate enabling the visualization of the oscillating flow patterns during the experiments. For a low power input $\left(4 \mathrm{~W} / \mathrm{cm}^{2}\right)$, the pulsating heat pipe filled with pure water is not able to work under low-g conditions, because the evaporator immediately exhibits dry-out conditions and the fluid oscillations stops, preventing heat transfer between the hot and cold side and resulting in a global increase of the temperatures. On the other hand, the FPPHP filled with the self-rewetting fluid runs also during the microgravity phase. The liquid rewets several times the evaporator zone triggering the oscillatory regime. The selfrewetting fluid helps both the start-up and the thermal performance of the FPPHP in microgravity conditions.
\end{abstract}

Keywords: Self-rewetting fluids; Pulsating Heat Pipe; Microgravity; Start-up conditions.

\author{
Abbreviations \\ FPPHP Flat Plate Pulsating Heat Pipe \\ PF Parabolic Flight \\ PHP Pulsating Heat Pipe
}




\section{Introduction}

Self-ReWetting Fluids (SRWFs) are binary or multi-component dilute aqueous solutions of long-chain alcohols with unusual surface tension behavior [1, 2]. For such mixtures, the presence of small proportions of alcohols in water changes dramatically the wetting and surface tension properties [3-9]. Contrary to ordinary liquids, in a given interval of temperatures, the surface tension becomes an increasing function of temperature. In addition to the variation induced by the preferential evaporation of the more volatile component, this leads to a reverse Marangoni effect along the liquidvapor interface towards the hotter region [10]. One of the most interesting applications of this effect is a spontaneous liquid inflow towards hot spots or dry patches of evaporation-based heat transfer devices [11].

Pulsating Heat Pipes (PHP) are passive heat transfer devices where a working fluid is distributed along a meandering capillary tube in the form of liquid slugs and vapor plugs separated by capillary forces. The heat exchange is triggered by thermally driven self-sustained oscillations of the working fluid. Phase change phenomena occur in the form of liquid film evaporation or flow boiling at the heated side and by condensation at the cold side. The application of a heat flux to the hot side pushes the evaporated vapor bubble towards the cold region, where they condensate giving to the working fluid the possibility to dissipate a significant portion of the power input. It is widely accepted that fluid movements are initiated by local pressure instabilities inside the tubes [12-14]. Therefore, the hydraulic regime governs the nature and the intensity of the global thermal exchange. Many parameters deserve special attention on the operation of a PHP [15-16], such as the number of turns, the dimensions of the system, the filling ratio and the thermo-physical properties of the working fluid. For instance, the inner diameter must be small enough that surface tension forces dominate gravitational forces and distinct liquid slug and vapor plugs can form. More U-turns give better thermal performances and a certain independence of the system orientation. Low filling ratio may cause the evaporator dry out, whereas with a higher filling ratio the device acts as a single phase thermosyphon. Working fluids with a higher surface tension increase the maximum allowable diameter for the slug-plug regime with a higher heat input required to maintain the pulsating flow. However, the influence of the different parameters on the system operation is not completely understood and a complex interplay of different hydrodynamic and phase-exchange phenomena needs to be taken into account in the modelling approaches. Unlike other heat transfer devices, the functioning of PHP is still very difficult to predict.

Among all parameters, the inclination of the system respect to the gravity vector as well as the absence of gravitational forces, strongly affect its operation. The presence of the characteristic slug and plug flow pattern instead of a stratified or annular flow in fact, mainly depends on the Bond number $\left(B o=\left(\rho_{l}-\rho_{v}\right) g D^{2} / \sigma\right.$ where $\rho_{l}$ and $\rho_{v}$ are the liquid and vapor densities, 
$\sigma$ is the surface tension, $D$ is the channel hydraulic diameter and $g$ is the gravity acceleration). On ground the Bo number gives the critical diameter at which the capillary forces cannot counterbalance the gravitational forces under static conditions (for water $D_{\text {crit }}=2\left(\sigma / g\left(\rho_{l}-\rho_{v}\right)\right)^{1 / 2} \approx 5.35 \mathrm{~mm}$ at $40^{\circ} \mathrm{C}$ ). In absence of gravity force, one of the most important questions for PHPs is the nature of the flow regime. Previous studies pointed out that PHPs can operate under microgravity conditions [17-22], even for the short time typical of the parabolic flights (about 22s of microgravity). In their studies the authors highlighted the difference of the hydraulic regimes under normal and microgravity conditions for both tubular [20] and flat plate PHP [22], using FC72 (Fluorinert ${ }^{\mathrm{TM}}$ refrigerant, $\mathrm{C}_{6} \mathrm{~F}_{14}$ ) as working fluid. The first experiment [20] considered a PHP with an internal diameter of 3mm, above the critical diameter of $\mathrm{FC} 72$, which is equal to $1.66 \mathrm{~mm}$ at $20^{\circ} \mathrm{C}$, with a transparent section on the upper part of the condenser. Observing the flow patterns through this transparent plate, it was possible to see that the liquid slugs completely fill the tube-channel, resulting in a plug-slug type flow. Such behavior may be considered as an encouraging result for the operation of PHP under microgravity conditions. The second experiment [22] consists in a Flat Plate PHP having a square channel section with dimensions of $2.5 \times 2.5 \mathrm{~mm}^{2}$. Also in this case, a slug-plug flow regime has been observed, with a tendency to dry out at the evaporator section for high power levels, accompanied by very intense fluid fluctuation, likely caused by the evaporation of small liquid plugs moving to the evaporator.

Since the role of surface tension driven flows became dominant with the decrease of the Bond number, i.e. reducing gravity, the self-rewetting effect becomes very important for PHPs working under low gravity conditions. In this work, a Flat Plate PHP (FPPHP) filled with ordinary liquid (water) and SRWF (aqueous alcohols solution) is investigated under variable gravity conditions on board a 'Zero-g' plane, during the $65^{\text {th }}$ ESA Parabolic Flight (PF) campaign, as part of the project INWIP ("Innovative WIckless heat Pipe systems for ground and space application"), recently funded by the European Space Agency. Two different working fluids with different thermophysical properties have been investigated. The experimental setup includes a transparent side enabling the visualization of the oscillating flow pattern during the experiments. The thermal performances in terms of temperatures, start-up levels and flow regimes have been characterized for the two working fluids for different power inputs in the 0-200W range. The paper is organized as follow: the experimental setup and the experimental procedure are described in the next section. Then, the experimental results achieved on board the zero-g plane are presented, including temperature measurements and flow visualization analysis. The results are discussed and the observations are explained on the basis of the different surface properties at the liquid-vapor interfaces.

\section{Materials and methods}

\subsection{Experimental setup}

The experimental set-up consists of a Flat Plate PHP (FPPHP) with a rectangular section having a transparent side. It allows the visualization of the oscillating flow pattern during the experiments (Fig. 1). The FPPHP is composed by a copper 
plate $\left(140 \times 210 \mathrm{~mm}^{2}\right)$ with a thickness of $3 \mathrm{~mm}$, where a single channel, meandered by $\mathrm{N}=11$ turns, and with a section of $3 \mathrm{X} 3 \mathrm{~mm}^{2}$, has been grooved, see Fig. 1b). A borosilicate glass $\left(134 \times 204 \times 5 \mathrm{~mm}^{3}\right)$ is glued on the upper face of the copper plate. In order to overcome the problem related to the different dilatation coefficients of the borosilicate and the copper, an elastic silicon adhesive (NUSIL $®$ CV7 2289 1P) is used. This silicon adhesive is slightly porous, and therefore a migration of non-condensable gases inside the PHP is possible, due to the fluid saturation pressure lower than ambient one. Since the presence of non-condensable gases is detrimental for the proper functioning of the PHPs, a sealed guard ring channel is used. The guard channel consists in a closed loop connected to an external vacuum tank that ensure a pressure lower than the pressure inside the PHP, see Fig. 1a) and Fig. 1b).

The cold source of the PHP is a grooved copper plate $\left(100 \mathrm{X} 140 \mathrm{~mm}^{2}\right)$ brazed directly on the rear face (Fig. 1c) and cooled with a liquid loop with a pump that circulates water between the condenser and an aluminum plate cooled by 15 fans/fins (Fig. 1d). The hot source consists of a $1 \mathrm{~mm}$ diameter heating wire embedded in a copper plate $\left(120 \mathrm{X} 10 \mathrm{~mm}^{2}\right)$ of thickness $2 \mathrm{~mm}$, brazed on the back of the PHP. Two pressure sensors (GE PTX5076-TA-A3-CA-HO-PS, absolute pressure of 1.5 bars, \pm 2.0 mbar) measure the pressure inside the PHP and inside the guard channel, respectively. The experimental cell is accommodated on the flight hardware with a double-containment. The outer container is a transparent box made in Plexiglas (Fig 1d), which isolates the ambient from potential fluid leakages in order to avoid any contamination and creates a closed box where the temperature can be controlled. In order to avoid the formation of condensation on the glass window, the temperature inside this box is kept at a higher value respect to the aircraft air and the cooling water temperatures using a heater resistor and a fan. The temperature of the cooling water as well as the air temperature inside the double containment are monitored and controlled during the experiments.

The experimental set-up is equipped with 10 T-type Thermocouples (TC, $\pm 0.5 \mathrm{~K}$ ). The temperatures at the hot source are measured with 3 TCs inserted between the back of the PHP and the heating plate, (EV_1 to 3 in Fig. 1b). The temperatures at the cold source are monitored measuring the inlet and outlet water temperatures with 2 TCs (Cond_in and Cond_out in Fig. 1d). The other sensors are used to measure the double containment temperature (2 TCs in the top and bottom parts of the double containment, Top_air and Bottom_air) and the temperature of the external air near the fans, the cooling plate and the pressure sensors.

Two digital cameras monitor the fluid oscillations inside the FPPHP. The first one (Camera_1) observes the entire PHP, while the second one (Camera_2) a restricted zone around five U-turns in the evaporator zone. The heating power is delivered by a power supply controlled with a LabVIEW® program. Finally, an accelerometer measures the intensity of the gravity acceleration during the parabolic flight. The experiments are controlled by two PCs for the acquisition of data as well as the control of the power input, the setting of the cameras and the video data recording. The synchronization of the 
two cameras is carried out by means of a LED mounted on the PHP, which is manually triggered through the acquisition program.

\subsection{Experimental procedure}

The FPPHP system has been tested in a set of short duration microgravity experiments, providing weightlessness with a residual acceleration of less than $10^{-3} \mathrm{~g}$. During a parabolic flight, the aircraft performs 31 parabolas in which microgravity conditions are obtained for a time approximately of 22s for each parabola. To compare the performances of the FPPHP filled with both pure liquids and SRWFs under microgravity conditions, two identical FPPHPs have been built and filled with pure water and a water/butanol mixture (4\%wt). Under normal gravity condition the capillary effects prevail on the gravity effects, since, for the $3 \mathrm{~mm}$ channel, the characteristic length is lower than the critical diameter for both liquids $(5,35 \mathrm{~mm}$ for water and 3,51mm for SRWF at $40^{\circ} \mathrm{C}$ ).

Fig. 2 shows the surface tension as a function of temperature for a concentration of $5 \%$ wgt of butanol in water [4, 23]. The water-butanol mixture shows a surface tension that, even if lower than the pure water, increases with the temperature above a certain threshold, which gives it the characteristic of being "rewetting". Table 1 shows other relevant thermophysical parameters of the two fluids for a nominal fluid temperature of $50^{\circ} \mathrm{C}$. The liquid mixture properties have been estimated through classical formulations: mean mass weighting for density, Orric-Erbar correlation for liquid viscosity [24], Teja-Rice correlation for thermal conductivity [25]. SRWF surface tension value has been set from experimental results of [4, 23] (Fig. 2). The derivative of the vapor pressure with respect to temperature $\left(\partial P_{v} / \partial T\right)$ for the SRWF has been evaluated by summing the water and butanol saturated vapor pressure, considering the butanol as a perfect gas with a mass concentration of $4 \%$ (a), and 20\% (b), respectively. The butanol mass concentration has been over-evaluated in value (b) in order to estimate the impact of a higher mass ratio of butanol in the vapor phase than in the liquid phase.

In addition, the wetting properties have been measured with a contact angle goniometer (OCA15, DataPhysics) using the changing volume technique for the quasi-static contact angles and the sessile drop method for the equilibrium contact angle. Details on the experimental setup are given in ref. [10]. Table 2 shows the advancing, receding and equilibrium contact angle for water and SRWF on copper surface. With the addition of butanol, the wettability of the working fluid can be effectively improved, and hence all the contact angles are lower.

During the parabolic flight, the system is tested in a favorable vertical configuration (Bottom Heat Mode). The temperature of the cooling water was regulated at $30^{\circ} \mathrm{C}$, while the air inside the confined zone was heated to about $40^{\circ} \mathrm{C}$, in order to avoid condensation of the working fluid on the top transparent side. Fig. 3 shows the typical experimental procedure during the flight. In order to check the start-up of the FPPHP under microgravity conditions, the system is switched on during the microgravity phase of the first parabola. Then the power is kept constant for a series of other 4 parabolas where 
the FPPHP exhibits normal, zero and hyper-gravity conditions. At the end, the system is switched off and the procedure repeated in another series of parabola changing the power input. The power input ranges from 50W to 200W with step of 50W for each series of parabolas.

\section{Experimental results}

The figures below show the time evolution of the temperatures under normal, hyper- (about 1.8g) and microgravity conditions. Here, only the results for power inputs of 100 and 200W are shown.

\subsection{The case of water filled FPPHP}

The first parabolic flight was carried out with water as working fluid. As well known in literature [26], water is a good working fluid for the PHP operation. Fig. 4a) and b) shows the temperatures and pressure measured during the flight for a power input of $100 \mathrm{~W}$ and 200W, respectively. The parabolic maneuvers can be clearly identified by the measured accelerations plotted on the same chart. The time between two consecutives parabolas is about three minutes.

In normal and hyper-gravity conditions, the temperature signals at the evaporator section (EV_1 to 3) are stable and show relatively low amplitude fluctuation during hyper-gravity with respect to the normal gravity phase, with a more homogenous and a small decrease of the FPPHP evaporator temperatures when the system goes from normal to the hypergravity conditions. On the other hand, temperature signals increase immediately under microgravity phases. An increase of $90 \%$ and $140 \%$ has been observed in the temperature difference between the evaporator and the cooling water compared to the normal gravity conditions for 100W and 200W heat loads, respectively. Obviously, the temperatures increase more rapidly for a power input of $200 \mathrm{~W}$ with respect $100 \mathrm{~W}$. Some fluctuations in the temperature signals are detected at beginning of the different parabolas (see Fig 4b), which are responsible of momentary decreases of the evaporator temperature, but then they stop, and the temperature signals rise until the end of microgravity without reaching steady state conditions. In all series of parabola, the FPPHP start-up is not occurring under the microgravity phases (see $1^{\text {st }}$ parabola in Fig. 4). The temperatures increase until the end of microgravity, and then drops down during the following hyper-gravity phase.

\subsection{The case of FPPHP filled with the SRWF mixture}

The experiments are carried out with a PHP identical to the PHP filled with water, so the working fluid is the only modified parameter between the two series of experiments. Fig. 5 shows the time histories of the temperatures and pressure acquired during the parabolic flight with the FPPHP filled with the SRWF mixture for a power input of 100W, 200W, respectively. The FPPHP filled with the SRWF shows a different behavior in both normal and microgravity conditions with respect to the one with water as operating fluid. 
As expected, under normal gravity conditions, the average temperature at the evaporator section is higher than the pure water, due to the relatively low power input. For instance, at $200 \mathrm{~W}$ the average evaporator temperature is about $50^{\circ} \mathrm{C}$ for the pure water (Fig. 4b)) and $55^{\circ} \mathrm{C}$ for the SRWF (Fig. 5b)). As discussed in the next section this temperature difference can arise from the temperature difference between the evaporator and condenser regions of the binary mixture. Contrary to water, at higher power level (Fig. 5b), the temperatures do not change when the system goes from normal to the hyper- gravity conditions which means that the PHP filled with SRWF is less sensible to the gravity effects. Under normal and hypergravity conditions at the beginning of the series of parabolas (left part of the curve), one of the three temperatures (Ev_1, to the left of the evaporator zone) remains higher but when the microgravity is reached the signal drops making the temperature at the evaporator section more homogenous. The PHP reaches the fully activation during this phase. Under microgravity conditions the increase of the evaporator temperature is much smaller than for pure water, especially at high power input (Fig. 5b and Fig. 4b). The PHP filled with SRWF shows better thermal performances during this specific transient phase. In particular, an average increase of $36 \%$ versus $140 \%$ of water has been observed in the temperature difference between the evaporator and the cooling water compared to the normal gravity conditions for 200W heat loads. Temperature fluctuations, i.e. oscillations of the working fluids, are still present until the end of the microgravity phase. These fluid oscillations which are responsible of heat transfers in the overall device, seems to be favored when the working fluid is the SRWF. In addition, it was possible to observe the start-up under microgravity phase. This is due to the relatively low value of the surface tension in case of SRWF. However, due to the absence of gravity (gravityassisted regime), the temperature differences observed under microgravity are higher than those observed in normal and hyper- gravity conditions.

\section{Discussion of the results}

Fig. 6 shows the thermal resistance for water and SRWF as a function of the power input, under normal gravity conditions and in vertical configuration. The thermal resistances have been evaluated by dividing the temperature difference between the mean evaporator temperature and the mean temperature of cooling water with the power supplied at the evaporator section. Data are taken from flight data at the end of each series of parabola (steady state conditions, see Fig. 4 and 5). As pointed out in Ref. [27] the thermal resistance of heat pipes filled with SRWF in gravity assisted regime is higher with respect to pure water at relatively low power input. This higher thermal resistance can be explained, by the temperature difference caused by the concentration difference, between the evaporator and condenser regions, that can be approximately estimated from the bubble point curve and the dew point curve in the phase diagram of the mixtures. The videos acquired during the experiments show that, in normal and hyper- gravity conditions, the regime was a slug/plug flow for the water, and slug/plug flow with presence of bubbles for the SRWF mixture (Fig. 7a). Otherwise, the FPPHP shows better performances under microgravity conditions when filled with 
SRWF, i.e. a lower temperature difference between evaporator and condenser section and a lower start-up power level. Unfortunately, thermal resistances cannot be plotted for microgravity tests, because they are too short to attain steadystate conditions.

The mechanisms responsible for the better performances are related to both surface tension and wetting properties of such mixtures. As shown in Fig. 7b), when the plug flows in the channel, there exists a capillary force due to the pressure difference between the advancing liquid slug front-end and the receding back-end $\left(\Delta F_{c a p} \cong 4 \sigma w\left(\cos \theta_{A^{-}} \cos \theta_{R}\right)\right.$, with $\sigma$ the surface tension, $w$ the channel width, $\theta_{A}$ and $\theta_{R}$ the advancing and receding angles given in Table 2). Due to the lower surface tension and the improved wettability, i.e. less contact angle hysteresis, this capillary force in SRWF is 58\% lower than water, see Table 3. In addition, numerical modelling shows that when the tube wall is heated, the fluid temperature is higher at the meniscus wedge (1) than at the meniscus center (2) due to the thinner liquid film [28]. In case of SRWF the surface tension will increase with the increasing temperature, so the temperature difference between the wedge and the center of the meniscus itself is responsible of a gradient of surface tension along the liquid/vapor interface. The preferential evaporation of the more volatile component also takes place, which results in a concentration gradient and an additional surface tension gradient. Both these mechanisms drive Marangoni convection from site 2 to site 1, see Fig. 7b).

On the other hand, in absence of gravity the average temperature at the evaporator section increases and a dry-out of the evaporator is observed. For both fluids, the only way to decrease the temperature of the evaporator zone under microgravity conditions is the oscillation of liquid plugs between the evaporator and the condenser sections. Fig. 8 shows a view of the PHP (left) and the associated temperatures (right) during the aircraft maneuver for water and a power input of 200W. Under microgravity conditions, at $t=520$ s a liquid plug moves progressively towards the evaporator zone. The plug reaches a superheated evaporator zone $(\mathrm{t}=530 \mathrm{~s})$ triggering a mass transfer mechanism in the whole PHP due to the vapor pressure increase during its rapid evaporation [22]. The associate heat transfer from slug/plug motion is responsible of the temperature oscillation shown in Fig. 8 (on the right). When the liquid plug oscillations stop, it prevents the energy transfer between the hot and the cold side and results in increasing temperatures.

In case of water (Fig. 4), during the $20 \mathrm{~s}$ of microgravity conditions the fluctuations are stopped and the liquid accumulates at the condenser section. Furthermore, the videos show also that only in one channel or, in rare cases, two channels, liquid plugs actually move towards the evaporator. Instead, in case of the SRWF, the liquid re-wet several times the evaporator zone triggering the oscillating regime (Fig. 9). The evaporator section of the FPPHP tends to remain wet during the microgravity phase. Liquid plugs in different channels move towards the PHP hot side (lower part in Fig. 9), where they evaporate triggering the oscillatory cycle. This vaporization leads to a new liquid-vapor distribution of the fluid 
inside the PHP, and to decrease the temperature. In the short time of the microgravity period, the evaporator never becomes completely dry as it appears for pure water.

In conclusion, the differences in the liquid plugs behavior between the two fluids arise from three main reasons: a rewetting phenomenon related to the surface tension and wettability properties of the mixture, which can spread liquid plugs towards the hotter evaporator region; the better mixture wettability, which facilitates the plug liquid flows decreasing the capillary resistance (Fig. 7); the higher saturation vapor pressure that increases the instabilities related to the pressure difference inside the channel, see Fig. 4 and Fig. 5. A comparison between the main thermophysical properties of both fluids is shown in Table 1 for a nominal fluid temperature of $50^{\circ} \mathrm{C}$. One can observe that most of the properties have values very closed ones to each other's (less than 10\% deviation for the density, viscosity, thermal conductivity and derivative of the pressure with respect to temperature), which may not justify the observed differences in flow behavior between the two fluids. The main divergence lies in the surface tension (more than $50 \%$ difference), but also in the wettability difference between both fluids (Table 2), and likely in the increase of the surface tension with temperatures above $50^{\circ} \mathrm{C}$ for the SRWF. Additional investigations are needed to study the butanol concentration effect on the overall heat transfer performance of the PHP under microgravity environment. Recent studies shown that even with a small amount of butanol added to water (2\%wgt) can increase the heat transfer coefficient [29].

\section{Conclusions}

In this study, a Flat Plate Pulsating Heat Pipe is investigated under variable gravity conditions on board the Zero-g plane during the $65^{\text {th }}$ ESA parabolic flight campaign. Two fluids have been investigated: an ordinary liquid (water) and a self-rewetting mixture (water/butanol) with interesting physical properties, i.e. a surface tension that increases with temperature, which may lead to a rewetting of the heated zones. The most important result shows that, even for low power input, for the proposed geometry, the FPPHP filled with pure water is not able to work under low-g conditions, because the evaporator immediately exhibits dry-out conditions, while on the other hand, the PHP filled with the selfrewetting fluid still operates during the microgravity phase. For this fluid, the liquid rewets the evaporator zone, triggering the oscillatory regime. Furthermore, the startup level occurs at lower heat loads in case of the SRWF mixture, and the evaporator temperature is smaller than for pure water, resulting in a lower thermal resistance. The FPPHP filled with the aqueous alcohol solution shows therefore a higher efficiency. On the contrary, under normal gravity and in vertical conditions, the FPPHP with water exhibits better performances.

\section{Acknowledgements}

This work was supported by the European Space Agency (ESTEC Contract number: 4000115115/15/NL/PG) as part of the MAP (Microgravity Application Promotion) project: “Innovative Wickless Heat Pipe Systems for Ground and Space 
Applications (INWIP)”. The authors wish to acknowledge the financial support of the European Space Agency and the technical help and organizational support of NOVESPACE.

\section{References}

[1] Y. Abe, 2004, About Self-Rewetting Fluids - Possibility as a New Working Fluid, Thermal Science and Engineering, 12 (3), pp. 9-18, 2004.

[2] R. Savino, R. Monti, Heat pipes for space applications, Space Technology, Vol. 25 N. 1, 2005.

[3] R. Savino, A. Cecere, R. Di Paola, Y. Abe, D. Castagnolo, R. Fortezza, Marangoni heat pipe: an experiment on board MIOsat Italian microsatellite, Acta Astronautica, Vol.65 (2009) pp.1582-1592.

[4] R. Savino, A. Cecere, R. Di Paola, Surface tension-driven flow in wickless heat pipes with self-rewetting fluids, Int. J. Heat Fluid Flow 30 (2) (2009) 380-388.

[5] R. Savino, R. Di Paola, A. Cecere, R. Fortezza, Self-rewetting heat transfer fluids and nano-brines for space heat pipes. Acta Astronautica, vol. 67, 9/10 (2011) pp. 1030-1037.

[6] R. Savino, A. Cecere, S. Van Vaerenbergh, Y. Abe, G. Pizzirusso, W. Tsevecos, M. Mojahed, Q. Galand, Some experimental progresses in the study of self-rewetting fluids for the SELENE experiment to be carried in the Thermal Platform 1 hardware, Acta Astronautica, 89 (2013) 179-188.

[7] A. Cecere, P. Toscano, R. Savino, Recent development on heat pipes for ground and space applications, IAC15-E4.2.8, 67th International Astronautical Congress, ), Guadalajara, Mexico, 26-30 September 2016.

[8] A. Cecere, R. Savino, S. Van Vaerenbergh, Surface tension driven flows in evaporative two-phase systems in microgravity conditions, in: 64rd International Astronautical Congress, Beijing, China, Paper IAC-13-A2.6.4, 2013.

[9] A. Cecere, C. Buffone, R. Savino, Self-induced Marangoni flow in evaporating alcoholic solutions, Int. J. Heat Mass Transfer, 78 (2014), 852-859.

A. Cecere, R. Di Paola, R. Savino, Y. Abe, L. Carotenuto, S. Van Vaerenbergh, Observation of Marangoni flow in ordinary and self-rewetting fluids using optical diagnostic systems, EPJ - Special Topics, Volume 192, Number 1 (2011) 109-120.

[11] R. Savino, D. De Cristofaro, A. Cecere, Flow visualization and analysis of self-rewetting fluids in a model heat pipe, International Journal of Heat and Mass Transfer 115 (2017) 581-591. 
[13] Khandekar, S., Charoensawan, P., Groll, M., Terdtoon, P., Closed loop pulsating heat pipes, part B: visualization and semi-empirical modeling, Appl. Thermal Eng., 23 (2003) 2021-2033.

[14] Liu, S., Li, J., Dong, X., Chen, H., Experimental study of flow patterns and improved configurations for pulsating heat pipes, J. of Thermal Sciences, 16 (2007) 56-62.

[15] Khandekar, S., Dollinger, N., Groll, M., Understanding operational regimes of closed pulsating heat pipes: an experimental study, Applied Thermal Engineering, 23 (2003) 707-719.

[16] Charoensawan, P., Khandekar, S., Groll, M., Terdtoon, P., Closed loop pulsating heat pipes, part A: parametric experimental investigations, Applied Thermal Engineering, 23 (2003) 2009-2020. Gu, J., Kawaji, M., Futamata, R., Microgravity performances of icro pulsating heat pipe, Microgravity Science and Technology, 16 (2005) 181-185.

[18] Mameli, M., Araneo, L., Filippeschi, S., Marelli, L., Testa, R., Marengo, M., Thermal response of a closed loop pulsating heat pipe under a varying gravity force, International Journal of Thermal Sciences, 80 (2014) 11-22. 17 th

[19] Iwata, N., Ogawa, H., Miyazaki, Y., Visualization of Oscillating Heat Pipe under microgravity, Proc. of International Heat Pipe Conference, Kanpur, India (2013) 6 p.

[20] Mangini, D., Mameli, M., Georgoulas, A., Araneo, L., Filippeschi, S., Marengo, M., A pulsating heat pipe for space applications: Ground and microgravity experiments, Int. J. of Thermal Sciences, 95 (2015) 53-63. S.,

[21] Ayel, V., Araneo, L., Scalambra, A., Mameli, M., Romestant, C., Piteau, A., Marengo, M., Filippeschi, Bertin, Y., Experimental study of a closed loop flat plate pulsating heat pipe under a varying gravity force, International Journal of Thermal Sciences, 96 (2015) 23-34.

[22] Ayel, V., Araneo, L., Marzorati, P., Romestant, C., Bertin, Y., Marengo, M., Visualization of flow pattern in close loop flat plate pulsating heat pipe acting as hybrid thermosyphons under various gravity levels, Heat Transfer Engineering, 40 (2018) (in press).

[23] Wu S-C., Study of self-rewetting fluid applied to loop heat pipe, Int. J. of Thermal Sciences 98 (2015) $374-$

380. 

estimation, experiment and data, Editor: Springer, 2007, 643 p., ISBN: 978-1-4020-5482-2.

[25] Teja, A.S., Rice, P., A generalized corresponding states method for the prediction of the thermal conductivity of liquids and liquid mixtures, Chem. Eng. Sc. 36 (1981) 417-422.

[26] Marengo, M., Nikolayev, V., Pulsating heat pipes: experimental analysis, design and applications, In: Thome, John R., ed., Encyclopedia of Two-Phase Heat Transfer and Flows, Vol. IV. World Scientific Publishing Company, Singapore (2018). ISBN 9789813234369. (in press).

Savino R., Abe Y., Fortezza R., Comparative study of heat pipes with different working fluids under normal gravity and microgravity conditions, Acta Astronautica 63 (2008) 24 - 34.

[28] Nikolayev V. S., Marengo M., (2018) Pulsating heat pipes: basics of functioning and numerical modelling, In: Thome, John R., ed., Encyclopedia of Two-Phase Heat Transfer and Flows, Vol. IV. World Scientific Publishing Company, Singapore (2018). ISBN 9789813234369 (in press).

[29] Sitar A., Golobic I., Heat transfer enhancement of self-rewetting aqueous n-butanol solutions boiling in microchannels, International Journal of Heat and Mass Transfer 81 (2015) 198-206 

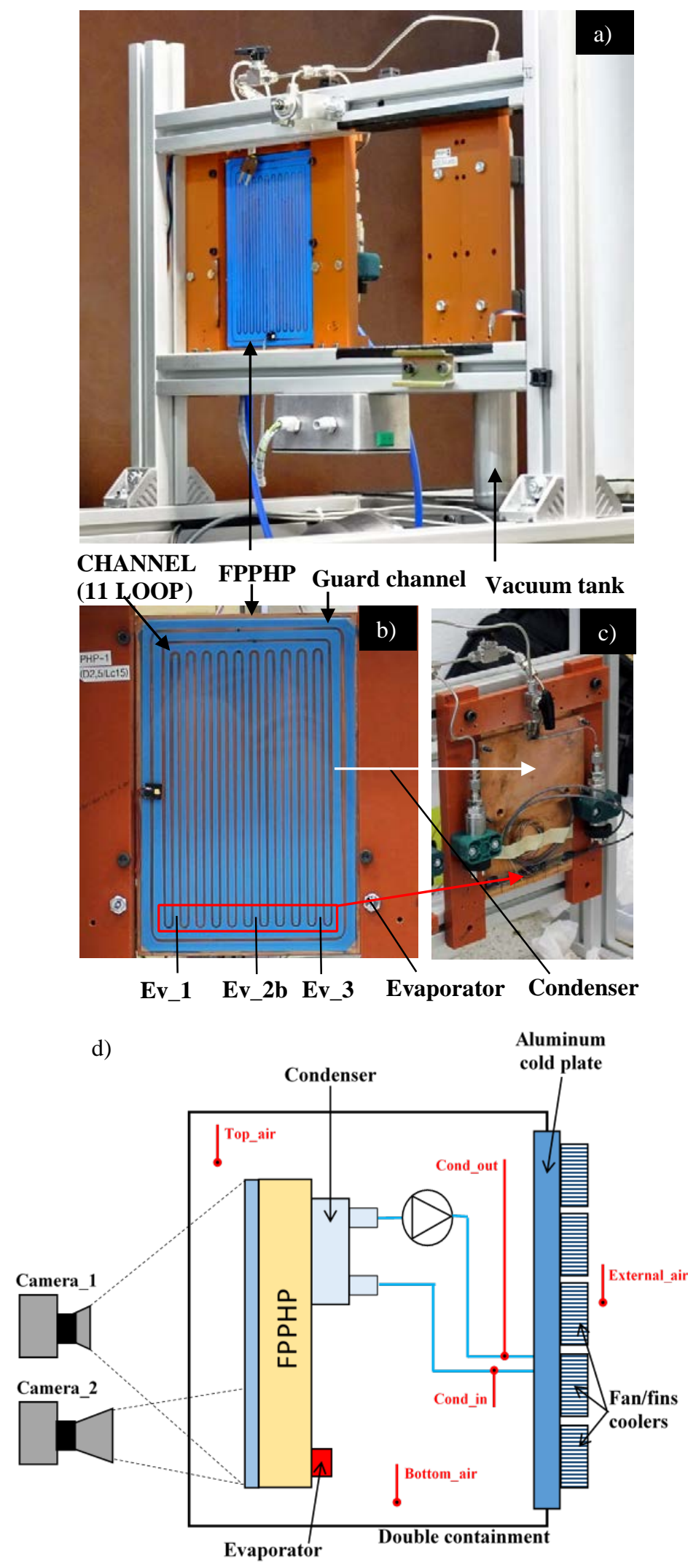

Fig. 1: Experimental setup: a) FPPHP and vacuum tank; b) Frontal view of the FPPHP; c) back view of the FPPHP where the hot and cold sources are mounted, d) schematic view of the double containment. 


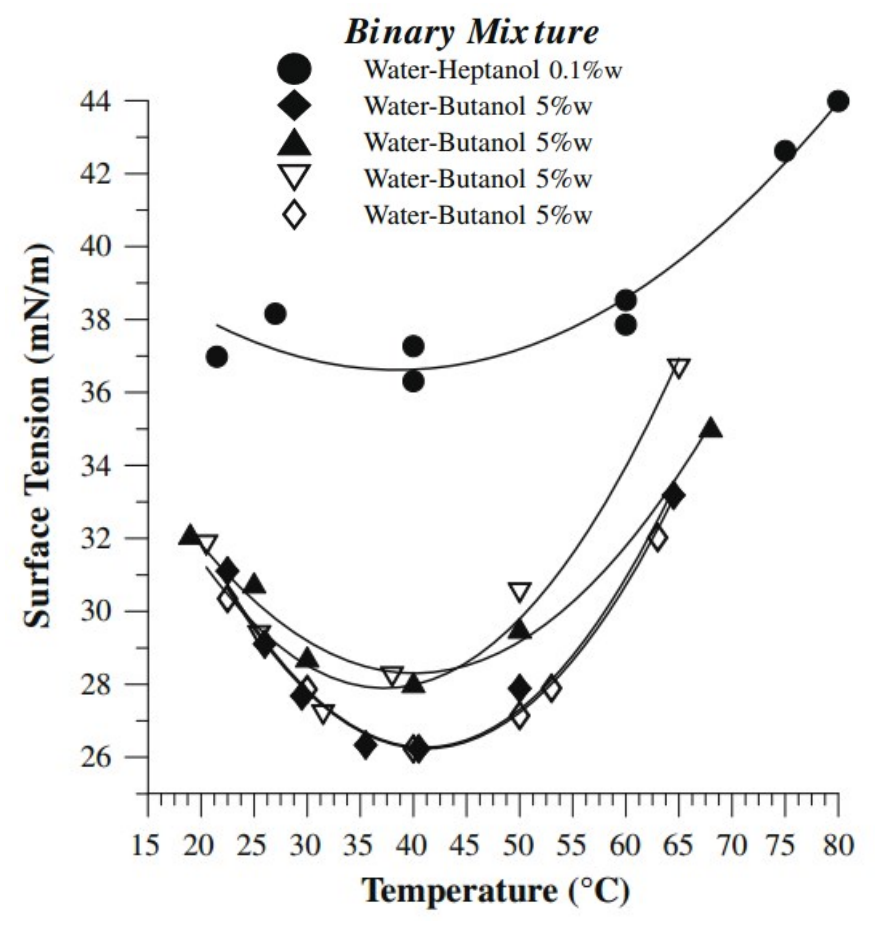

Fig. 2: Measurements of surface tensions for a concentration (\% weight) of $5 \%$ of butanol in water [4, 22]. The mixture shows a surface tension that increases with the temperature above a certain threshold (self-rewetting fluid). 
Fig. 3: Experimental procedure: the system is switched on during the microgravity phase of the first parabola, then the power is kept parabolas where the

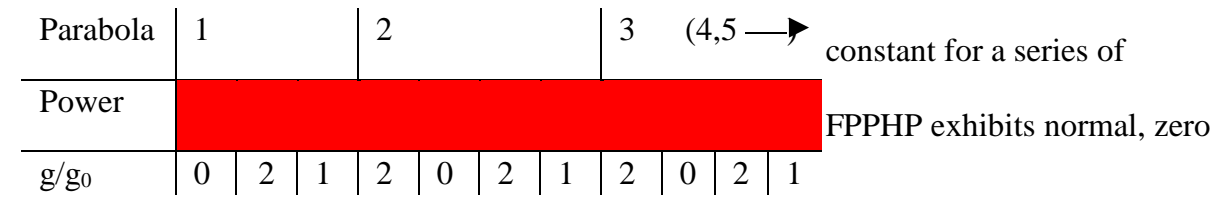
and hyper-gravity conditions. 

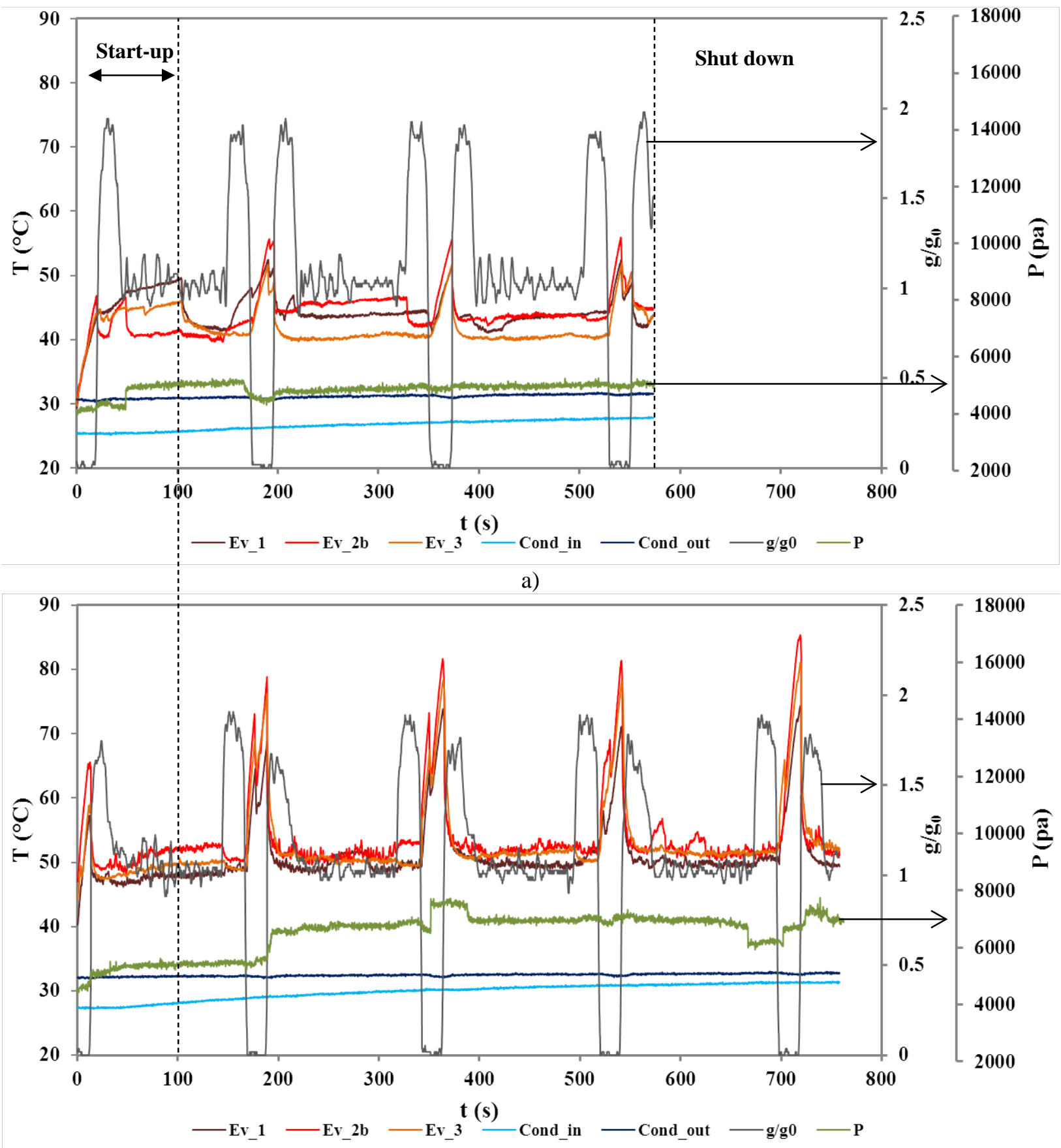

b)

Fig. 4: Time histories of the temperatures in the FPPHP filled with water. Power input of 100W (a), 200W (b). 


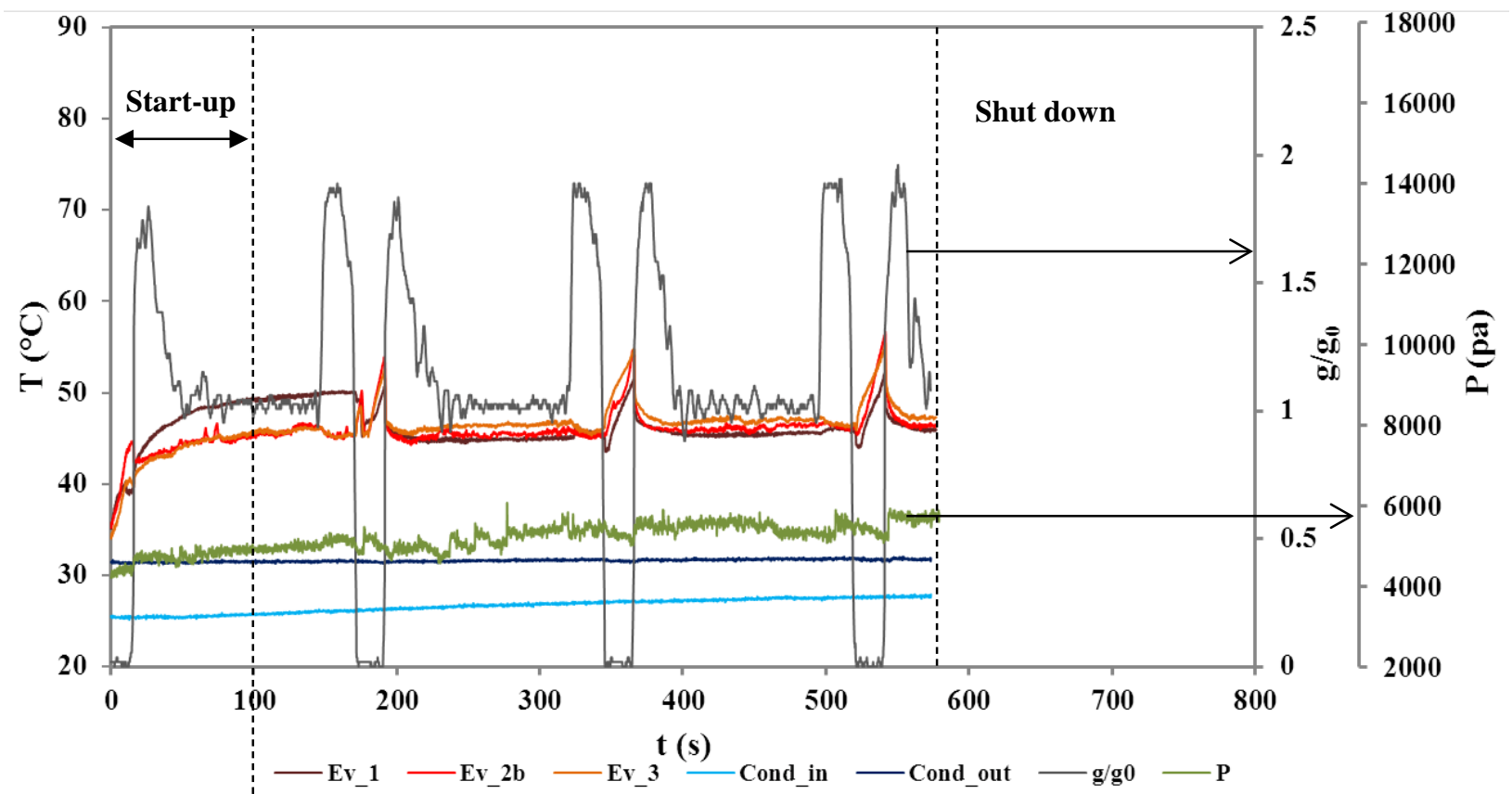

a)

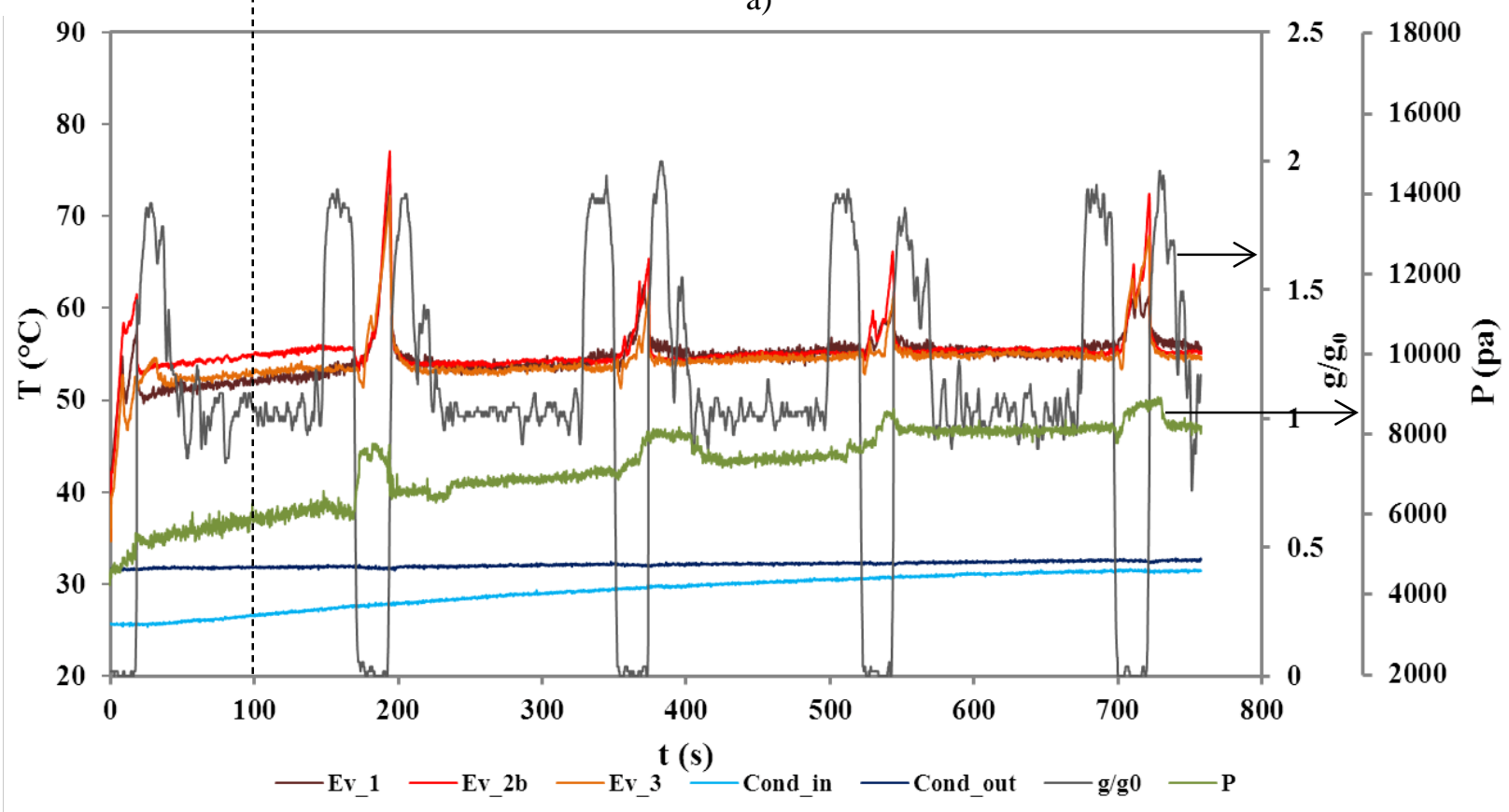

b)

Fig. 5: Time histories of the temperatures in the FPPHP filled with SRWF. Power input of 100W (a), 200W (b). 


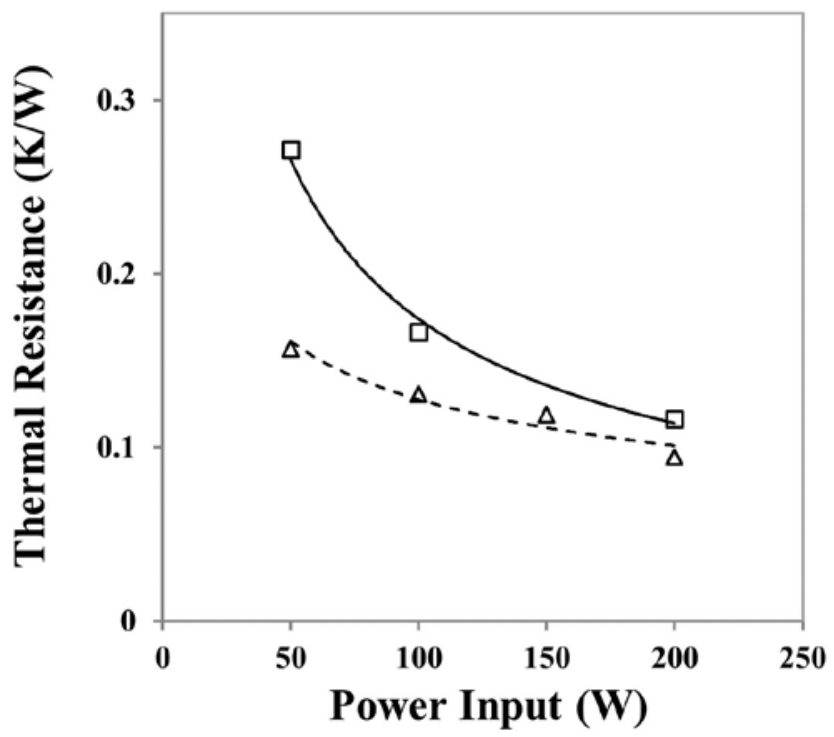

Q SRWF $\quad \triangle \mathrm{H} 2 \mathrm{O}$

Fig. 6: Thermal resistances of the FPPHP filled with water and SRWF, during normal gravity conditions as functions of heat input. 

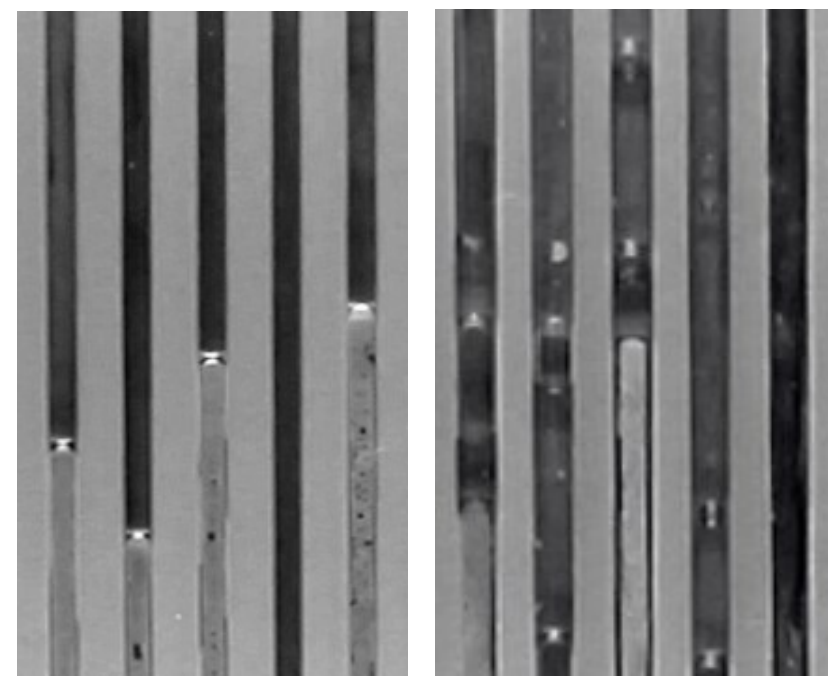

WATER

a)

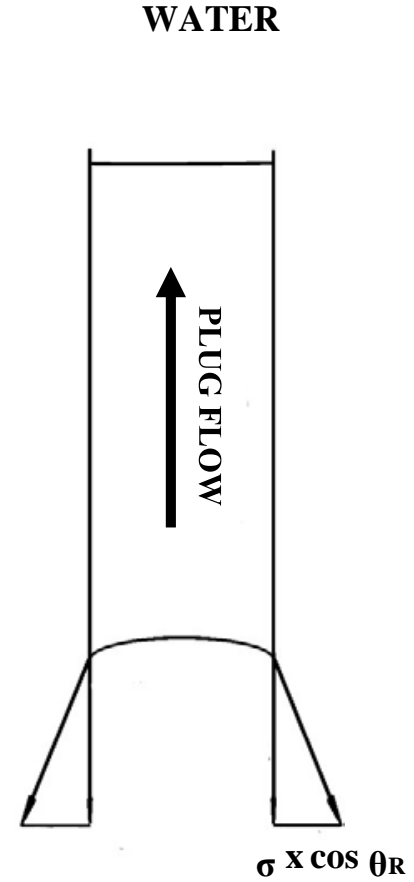

SRWF

$\sigma x \cos \theta \mathrm{A}$

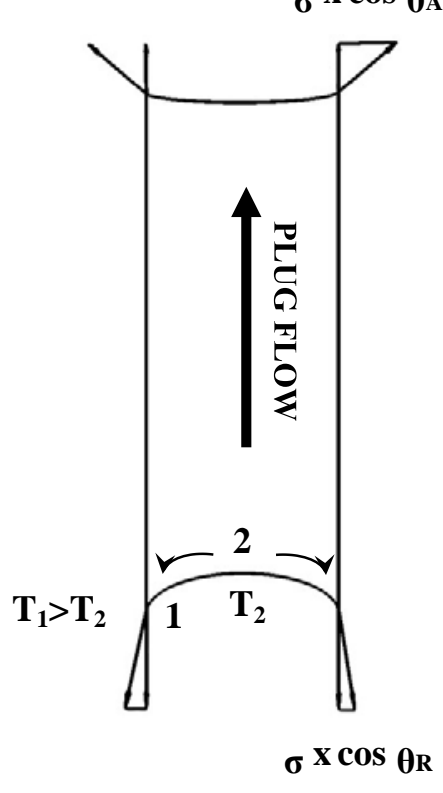

b)

Fig. 7: a) flow regime for water and SRWF under normal and hyper-gravity conditions (power input $200 \mathrm{~W}$ ). b) a possible explanation of the better performance of the SRWF due to the surface properties at the slug vapor interface (the arrows show the direction of the reverse Marangoni convection at meniscus interface in case of SRWF). 

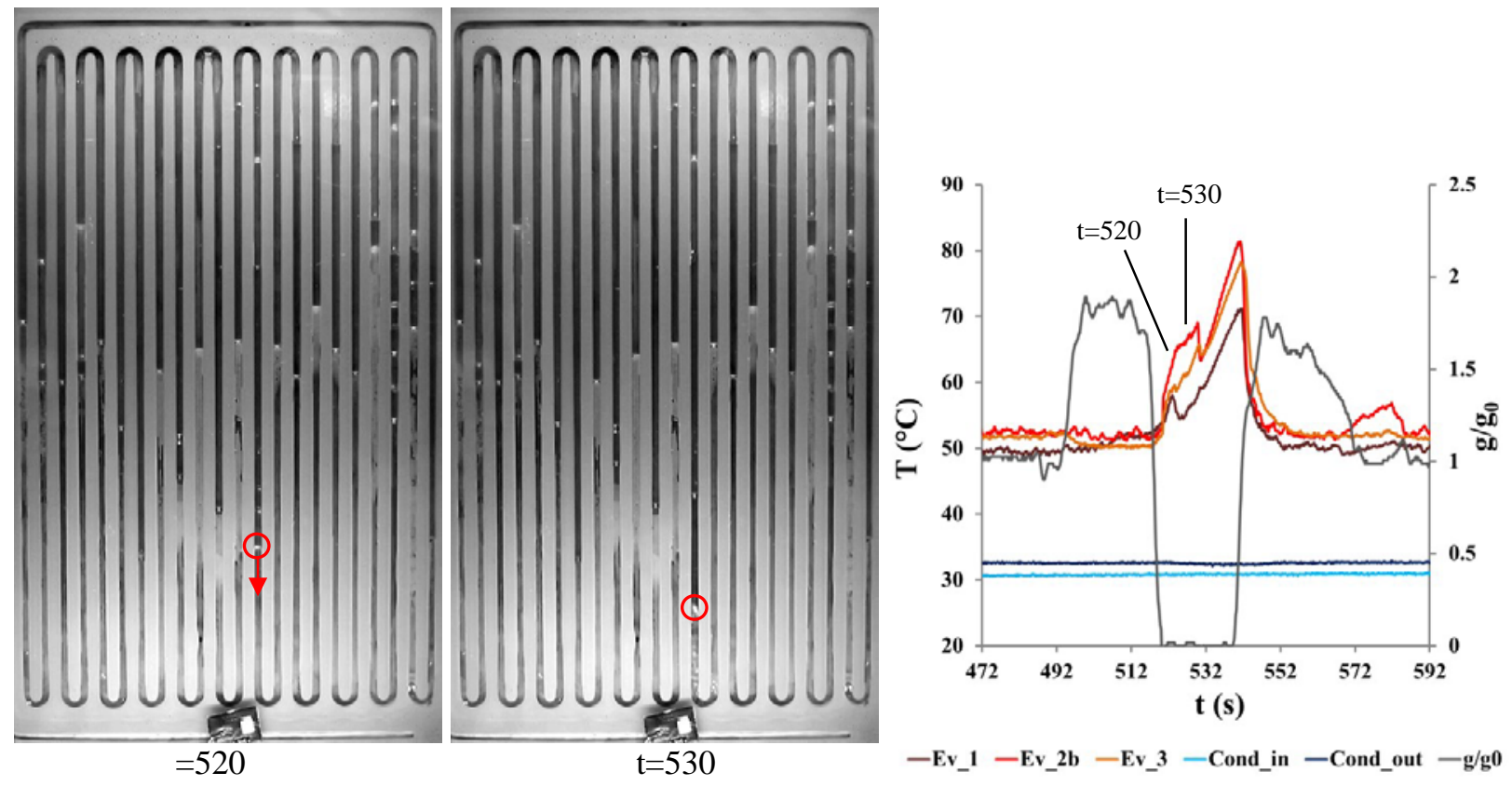

Fig. 8: View of the FPPHP (left) flow pattern and associated temperature (right) under microgravity condition for the 
water. Power input: 200Watt. 


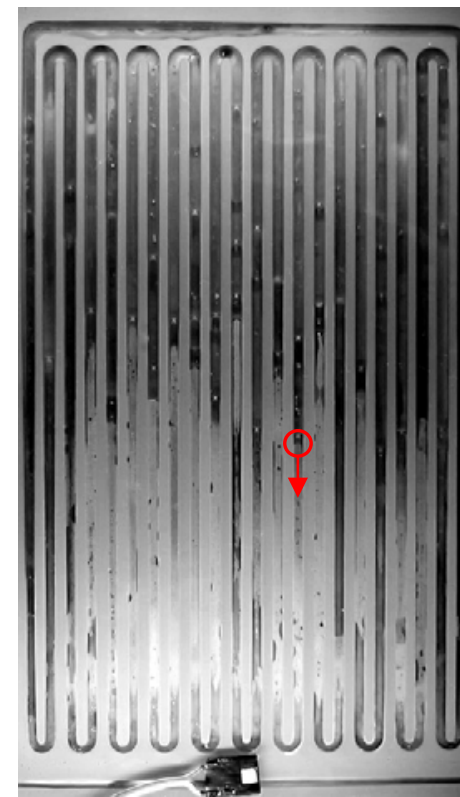

$\mathrm{t}=530$

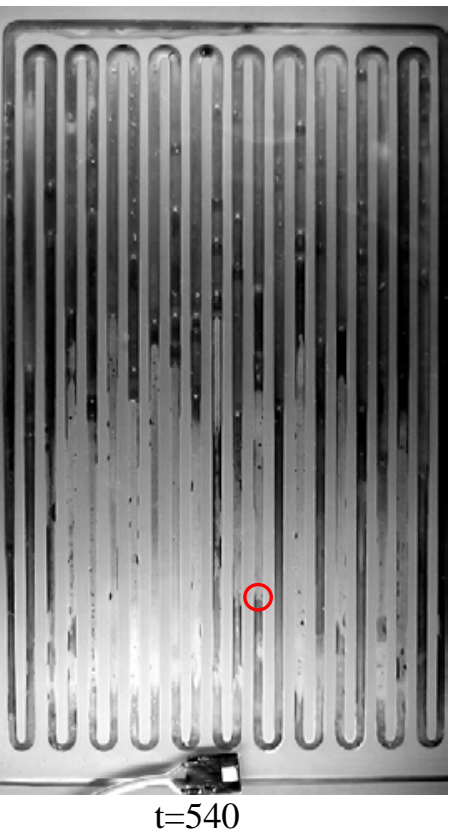

$\mathrm{t}=540$

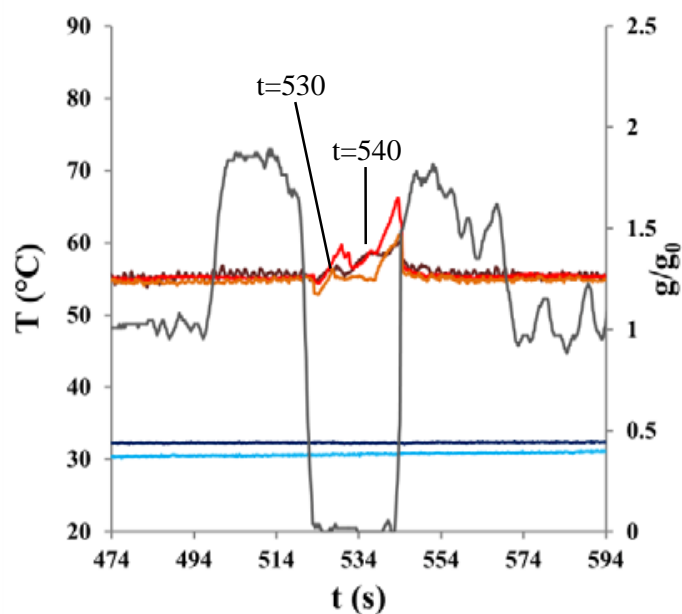

$-E v \_1-E v \_2 b-E v \_3-$ Cond_in - Cond_out $-\mathrm{g} / \mathrm{g} 0$

Fig. 9: View of the FPPHP (left) flow pattern and associated temperature (right) under microgravity condition for 
water-butanol mixture. Power input: 200Watt. 
Table 1: comparison of thermophysical properties for water and SRWF at $50^{\circ} \mathrm{C}$.

\begin{tabular}{|c|c|c|c|c|c|}
\hline Fluids & $\begin{array}{l}\rho l \\
\left(k^{\prime} \cdot m^{-3}\right)\end{array}$ & $\begin{array}{l}\mu_{I} \\
\text { (kg.m-1S-1) }\end{array}$ & $\begin{array}{l}\lambda_{1} \\
(\mathrm{~W} \cdot \mathrm{m}-1 \mathrm{~K}-1)\end{array}$ & $\begin{array}{l}\sigma \\
\left(\mathrm{N} \cdot \mathrm{m}^{-1}\right)\end{array}$ & $\begin{array}{l}\left(\partial P_{v} / \partial T\right) \\
\left(P_{a} \cdot K^{-1}\right)\end{array}$ \\
\hline Water & 988 & $5 \times 10^{-4}$ & 0.604 & $6.8 \times 10^{-2}$ & 613,8 \\
\hline SRWF & 979 & $5.5 \times 10^{-4}$ & 0.564 & $3.2 \times 10^{-2}$ & 618,8-639 \\
\hline
\end{tabular}


Table 2. Comparison between the contact angles of the working fluids on copper surface.

\begin{tabular}{|c|c|c|c|}
\hline \multicolumn{2}{|c|}{ Liquids $\theta_{A}$} & $\boldsymbol{\theta}$ & $\theta_{R}$ \\
\hline Water & $84.2 \pm 1.9$ & $82.2 \pm 1.9$ & $52.1 \pm 1.7$ \\
\hline$\underline{\text { SRWI }}$ & $72.3 \pm 2.3$ & $53.6 \pm 1.3$ & $36.5 \pm 1.8$ \\
\hline
\end{tabular}

$\theta_{\mathrm{A}}$ : Advancing angle, $\theta$ : Static equilibrium angle, $\theta_{\mathrm{R}}$ : Receding angle 
Table 3: comparison of the capillary force for water and SRWF.

\begin{tabular}{|c|c|c|c|c|c|c|}
\hline \multicolumn{2}{|c|}{ Liquids $\theta_{\mathrm{A}}\left({ }^{\circ}\right)$} & $\theta\left({ }^{\circ}\right)$ & $\theta \mathrm{R}\left({ }^{\circ}\right)$ & $F_{\text {cap, front }}(\mathrm{N})$ & Fcap, en & $\Delta F_{\text {cap }}(\mathbf{N})$ \\
\hline Water & $84.2 \pm 1.9$ & $82.2 \pm 1.9$ & $52.1 \pm 1.7$ & $8.6 \mathrm{E}-5$ & $5.2 \mathrm{E}-4$ & $-4.3 E-4$ \\
\hline SRWF & $72.3 \pm 2.3$ & $53.6 \pm 1.3$ & $36.5 \pm 1.8$ & $1.1 \mathrm{E}-4$ & 2.9E-4 & $-1.8 \mathrm{E}-4$ \\
\hline
\end{tabular}

